\title{
FUELS AND LUBRICANTS AND CARBON COMPOSITES FOR MODERN AVIATION
}

\author{
Doshlov Oleg Ivanovich \\ Irkutsk National Research Technical University \\ Professor of the Department of Chemical Technology \\ Irkutsk, Russia \\ doshlov125@mail.ru
}

Gusev Igor Nikolayevich

Irkutsk National Research Technical University

Head of the Department of Aircraft and Aircraft Maintenance, Professor

Irkutsk, Russia

\begin{abstract}
The paper reports on fuels and lubricants as well as composite materials used for modern aviation. Fuels for jet aviation and their characteristics are discussed. Various petroleum oils and specialty liquids are analyzed. Possible applications of petroleum-derived modern composites for MS-21 are considered. Perspectives of production of promising fuels and composites are evaluated.
\end{abstract}

Keywords-jet fuels, synthetic aviation working fluids, petroleum oils, additives, composites.

\section{INTRODUCTION}

In air-jet engines, three types of fuels differing in their fractional composition are used. The first type of reactive fuels, which is the most common, is kerosene with a boiling range of $135 / 150-250 / 280^{\circ} \mathrm{C}$. These include T-1, TS- 1 and $\mathrm{RT}$. The second type is a fuel with a broad fractional composition $\left(60-280^{\circ} \mathrm{C}\right)$, which represents a mixture of gasoline and kerosene fractions (T-2 type of fuel). The third one is jet fuel for supersonic aircrafts - heavy-weighted kerosene that is a gasoil fraction with boiling points of $195-315{ }^{\circ} \mathrm{C}$. This type includes T-6, T-8B fuels.

These fuels are commonly divided into those for subsonic or supersonic aircraft engines. This division is due to the temperature conditions for using fuel in these engines and differs significantly. Fuel for supersonic aviation engines is heated by aerodynamic heating of the whole structure of the aircraft. At a flight speed more than twice the speed of sound $(2 \mathrm{M})$, the fuel can be heated to $150-180^{\circ} \mathrm{C}$ (Table 1 ).

Very stringent quality requirements are imposed on reactive fuels for supersonic aviation. In particular, they should burn steadily without carbon deposits in the fast-moving air flow with large surpluses of the latter, ensure a reliable start of the

\author{
Podgorbunskaya Tatiana Anatolyevna \\ Irkutsk National Research Technical University \\ Associate Professor of the Department of Chemical Technolo- \\ gy \\ Irkutsk, Russia
}

\section{Doshlov Ivan Olegovich}

Irkutsk National Research Technical University

Post-graduate student of the Institute of Energy

Irkutsk, Russia

doshlov125@mail.ru

engine in all conditions, have the maximum possible heat of combustion.

In the course of development of aviation technology, requirements for fuels are becoming even more stringent. For instance, the progress in supersonic aviation makes increasingly tougher demands for thermo-oxidative stability of fuels. The increased capacity of fuel tanks of transport and bomber aircrafts has accelerated a fueling process. However, this leads to accumulation of static electricity charges in the fuel that requires application of special antistatic additives. The requirements for high-density of fuels for high-speed aircrafts with a long duration of supersonic flight are caused by high consumption of fuels. They are especially important for aircrafts with limited capacity of fuel tanks such as fighters. In supersonic aircrafts, the space for placing fuel is limited. Therefore, such aircrafts require a fuel of high density and combustion heat to ensure higher engine power and a longer flying range. 
TABLE I. TCHARACTERISTICS OF SUBSONIC AND SUPERSONIC EUROPEAN TRANSPORT AIRCRAFT.

\begin{tabular}{|l|c|c|}
\hline Characteristic & $\begin{array}{l}\text { Subsonic aircraft VC100 engine } \\
\text { Corway RCA 43D }\end{array}$ & $\begin{array}{l}\text { Supersonic } \\
\text { aircraft Concorde } \\
\text { engine Olympus } \\
593\end{array}$ \\
\hline Maximum total net weight, kg & 150700 & 167500 \\
\hline Maximum amount of fuel consumed & 69300 & 83200 \\
\hline Ratio & 0.46 & 0.54 \\
\hline Cruising speed & 880 & 2320 \\
\hline Fuel consumption at cruising mode, l/pass & 0.036 & \\
\hline
\end{tabular}

These requirements can be satisfied using fuels of special chemical composition, for example, those containing naphthenic and isoparaffinic hydrocarbons. The fuels are prepared by isolation of the corresponding fractions upon primary distillation of oil. Certain grades of fuels are subjected to hydroforming to remove sulfur, acids, and part of aromatic hydrocarbons. In view of these severe requirements for chemical composition and production technology (without deep chemical conversion), jet fuels can be obtained only from certain (in terms of chemical composition) oils, whose resources are limited and nowadays are almost exhausted.

Currently, the Russian regulatory standards provide for the production of jet fuel grades:

- $\quad$ subsonic TS-1, T-1 (similar to the USA ER-4);

- transitional RT, which can be used for both sonic and supersonic aircrafts (analog-USA ER-5);

- $\quad$ supersonic T-6, T-8B (similar to USA 1P-6).

Fuel T-2 is not currently manufactured and is considered as a reserve one. Fuel T-8B was first employed in 1968 for the first domestic civil supersonic aircraft Tu-144. It can also be used for military supersonic aircrafts and other machinery.

Apart from aircrafts, fuel T-6 is used in the following products of missile weapons as the main (duplicate) brand:

- $\quad$ ZM80, ZM82 anti-ship missiles;

- $\quad \mathrm{X}-55$ strategic cruise missiles;

- ZM14, ZM45 high-precision cruise missiles in the composition of the RK " Caliber»;

- $\quad$ R-500 cruise missiles in the composition of the RK "Iskander-M".
Jet fuel T-6 refers to thermostable air-kerosene and represents a gas-oil fraction $\left(195-315^{\circ} \mathrm{C}\right)$ of oil (or secondary processing products) direct distillation. The fuel is subjected to deep hydrogenation to remove sulfur compounds, resins and unstable hydrocarbons and to convert the aromatic hydrocarbons into cyclanes. Antioxidant and, in some cases, anti-wear additives are added to the fuel. It possesses a high density and flash point, enhanced combustion heat, a low content of sulfur and aromatic hydrocarbons and has a high thermal stability.

The unique equipment of steam-phase hydrogenation units allowed one to receive only from one straight-run kerosenegas oil fraction $\left(190-320^{\circ} \mathrm{C}\right)$ of Troitsko-anastasievskaya oil of the fourth horizon deep-hydrogenated high-quality jet fuel in one stage at high pressures (25-30 $\mathrm{MPa})$, temperatures (380$400{ }^{\circ} \mathrm{C}$ ) and low volume velocities (1-2 H1) at a special catalyst loaded into the reaction columns.

Multistage technology of production and shipment of fuel T-6 includes the following stages at the facilities of the refinery factory (RF), chemical plant (CP) and commodity production (TSP):

- $\quad$ hydrogenation of raw materials under pressure in the presence of a special catalyst on high-pressure units (blocks 130,131,136);

- $\quad$ blow-off and alkalization of the hydrogenated feed from hydrogen sulfide followed by washing from traces of alkali with water (objects 149/172,1669) CP;

- $\quad$ atmospheric and vacuum distillation to release distillate of fuel T-6 on installation $209 \mathrm{RF}$;

- $\quad$ addition of additives to the distillate fuel RF;

- $\quad$ certification and shipment of TSP fuel. (4) 


\section{PROBLEM STATEMENT}

Synthetic oils based on poly-a-olefins, esters and, for some engines, oligoorganylsiloxanes are used for heat-stressed GTE. The total share of mineral oils used for aircrafts equipped with Russian engines is about $90 \%$, while in foreign countries the share of synthetic oils is close to $100 \%$. The development of engine construction in accordance with modern requirements to increase the temperature of aviation oils determines the need to increase the volume of production of synthetic oils in our country. Abroad, most common types of synthetic oils for an aircraft gas-turbine engine are oil-based esters, including esters of polyatomic alcohols and monocarboxylic acids, and esters of dibasic acids and monoalcohols. In Russia, however, ester oils occupy a relatively modest place.

The main volume of synthetic oils in our country is made from components manufactured by foreign companies: Exxon Mobil, Chevron, Neste Oil, Ciba, Phillips Chemicals, Cognis, BP Chemicals, NyCo, Uniqema, etc. The upper limit of thermal oxidation stability of these oils is $200-225^{\circ} \mathrm{C}$. Among the synthetic oils produced in Russia, the most common in modern domestic heat-stressed technology (with an oil temperature at the outlet of $200^{\circ} \mathrm{C}$ ) is the IPM-10 oil, developed in the research Institute of NP in the late seventies of the last century on a unique low-viscosity isoparaffinic-based IPMA-10.

In 1991, Novokuibyshevsk refinery dismantled a unique plant for isomerization of paraffinic raw materials to obtain the IPMA-10 basis, and the planned production at Volgograd refinery was not launched.

For KA-7.5, due to the need to provide the aviation industry with universal year-round oil to improve the safety and reliability of flights, in 2004-2005 LLC "Kvalitet-Avia" with the participation of JSC "VNII NP", workers have carried out the works on the selection of the basic component and additives to it [5]. As a result, a promising unified thickened multigrading aviation oil KA-7.5 (TU 38.4011103-2005 Rev. 1) for turboprop and turbo-fan aircraft engines has been developed. Currently oil KA-7,5, modified by the FAA "25th state research Institute of chemmotology of the Ministry of Defense of Russia", are produced by "Kvalitet-Avia" and passes the control and flight tests.

LZ-240 and B-3B oils are produced in Russia from imported components on the basis of pentaerythritol and fatty acids C5-C10 LZ-240 (TU 301-04-010-92) and B-3B (TU $38.101295-85)$. It is used in GTE and helicopter reducers, as well as in turboprop engines of AN-3, Il-114 and some others aircrafts. LZ-240 oil, developed by JSC "Zavod im. Shahumyan", has the best performance characteristics. In the case of oil B-3B application, Captax EP additive precipitates.

In case of PTS-225, the works of JSC "VNII NP" on the improvement of B-3B oil and the increase of oxidative stability of lubricating oils for turbojet engines have led to the development of a highly stable synthetic oil PTS-225 (TU 38.401-58-1- 90) basing on esters of PENTAERYTHRITE and fatty acids C5-C9. In terms of its physical, chemical and operational characteristics, this oil meets most closely (as compared to other domestic oils) the requirements of foreign regulatory documentation. However, due to the lack of raw materials at the present time, PTS-225 is not produced.

VNIINP-50-1F and VNIINP-50-1-4U, on the basis of the diisooctyl alcohol ester and sebacylic acid, produced by Russian enterprises, the following aviation oils have been developed by JSC "VNII NP": VNIINP-50-1-4F (GOST 13076-86) with additives that enhance anti-wear properties and thermooxidative stability is intended for use in engines with oil temperature at the output to $175^{\circ} \mathrm{C}$ and in the turbo-cooler; VNIINP- 50-1-4U (TU 38.401-58-12-91), containing an effective composition of anti-oxidizing additives that allow its using at temperatures from -60 to $200^{\circ} \mathrm{C}$ (short-term overheating is permitted to $225^{\circ} \mathrm{C}$ ).

VNIINP oil-50-1-4U, one of the main oils in military equipment, is permitted to use in all aircraft GTE. It can replace VNIINP oil-50-1-4F. It is completely compatible with VNIINP oil-50-1-4F, and does not require replacement of rubbers and structural materials. This oil finds extensive application in military machinery (e.g., in MiG-29). It is recommended for hi-tech equipment.

The fundamental problem in the production of synthetic gas turbine oils is the lack of domestic basic components: almost all synthetic oils are manufactured from imported materials. Especially challenging production is that of high-quality PAOM and pentaerythrite esters. While the use of imported raw materials is quite acceptable for civil aviation in the modern globalization of markets, it is unacceptable for military aviation, which is a strategic guarantor of Russia's national security. It is unlikely that Russian companies will invest their efforts into creation of these expensive low-tonnage capacities. In the near future, domestic production of synthetic components of gas turbine oils should become a priority in the investment policy of the government of the Russian Federation.

\section{RESULTS}

New domestic synthetic aviation working fluids

Currently, the most of aviation working liquids (WL) are produced from petroleum oils obtained via extraction and hydrocatalytic processes. The main disadvantage of oil WL is a high fire-explosion hazard and a tendency toward mechanical destruction. This deteriorates viscosity-temperature properties of WL, increases their foam and sludge formation, and decreases resource of hydraulic units and systems [1-3].

To equip modern aircrafts with competitive domestic WL, a new domestic working fluid ASHIM has been designed and manufactured.

ASHIM (aviation synthetic hydraulic oil) is the first domestic synthetic WF, its viscosity being $9 \mathrm{~mm}^{2} / \mathrm{s}$ at $50{ }^{\circ} \mathrm{C}$. The liquid contains an improved combination of functional additives (thickening, antioxidant, anti-wear and anti-foam, etc.). In terms of performance characteristics, ASGIM is superior over the traditionally exploited liquids. It is impossible to design completely non-inflammable liquid. Therefore, the requirements for incombustibility of liquids have been replaced by those to their fire explosion safety. Phosphoric acid esters are promising basic components of fire explosion safe 
WF due to their fire-resistance and satisfactory combination of thermal stability, viscosity-temperature and lubricating properties. The disadvantages of such WL include high toxicity, chemical aggressiveness and poor compatibility with hydrocarbon oils [4]. Now these WF are applied in the majority of hydraulic systems of civil aviation aircrafts (Tu-214, Il-114, Be-200). The investigations into the improvement of phosphate WL are mainly focused on the increase of thermaloxidative and thermal stability, the improvement of hydrolytic stability. And expansion of the operating temperature range.

To improve the competitiveness of domestic phosphate liquids, NIISU together with CIAM, 25 GosNII Ministry of Defense, research Institute NI and others have developed a new domestic working fluid VGZH. A pilot batch of this liquid has been produced by JSC "NK "Rosneft" - M3 "Oil".

This fire and explosion safe hydraulic fluid is the newest domestic WL $\left(9 \mathrm{~mm}^{2} / \mathrm{s}\right.$ at $\left.50{ }^{\circ} \mathrm{C}\right)$ obtained from a mixture of phosphoric acid esters. It possesses thermo-oxidative and hydrolytic stability. The study, conducted in CIAM, has shown that these properties of INFLOW are superior to those of ngj$5 \mathrm{U}$. For instance, INFLOW has a lower viscosity at $-60{ }^{\circ} \mathrm{C}$ after oxidation, the acid number of the oxidized oil being in the range of convergence. In terms of hydrolytic stability, this liquid has better values of acid number, $\mathrm{pH}$ and copper corrosion. The achieved improvements were obtained by changing the composition of the base mixture of esters and using an imported additive that prevents their destruction. But INFLOW in comparison NGJ-5U has a lower flash point, high foamability, reduced anti-wear ability and lower stability after scoring.

\section{Carbon fibers and composites}

The introduction of carbon fibers into polymer materials has allowed a fundamentally new class of structural materials, carbon plastics. They represent composite materials based on a polymer matrix reinforced with continuous or discrete carbon fibers.

MS-21 was conceived as an innovative aircraft. The main innovation is the following. For the first time in Russia (and, earlier than at many leading aircraft manufacturers), the aircraft will have a composite wing. It is fundamentally important that we are talking not just about the widespread use of composites, but about their use in high-loaded structures. This, in turn, has a significant impact on the aerodynamic layout and aerodynamics of the aircraft. Traditionally, aerodynamics tries to increase the elongation of the wing (the ratio of wingspan to the middle chord of the wing), as this helps to reduce the resistance. However, this aspiration rests on increasing the mass of the structure, which makes us look for an optimum compromise.

Depending on the type of reinforcing carbon material, carbon plastics are divided into carbon fibers, carbon-cloth composites and carbon-fiber composites. Carbon fibres are manufactured using continuous carbon threads and bundles. They have low thermal conductivity and electrical conductivity, but still their thermal conductivity is $1.5-2$ times higher than that of glass fibers. They have a small and stable coefficient of friction and have good wear resistance. The temperature coef- ficient of linear expansion of carbon fibers at $20-120^{\circ} \mathrm{C}$ is close to zero.

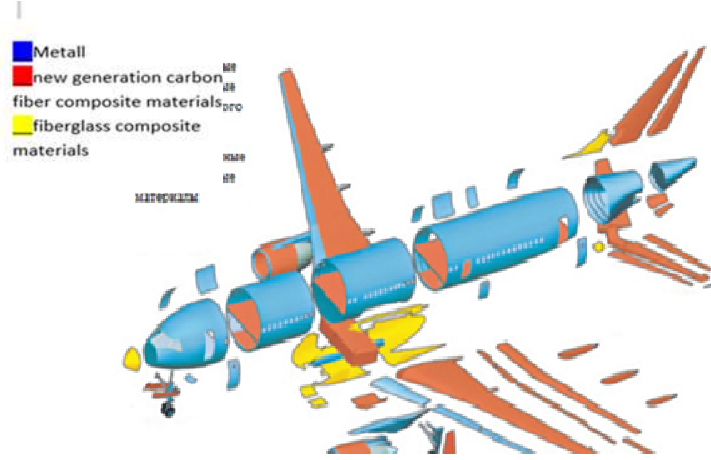

Fig. 1. Distribution of materials in MS 21

\section{CONCLUSION}

Despite the objective difficulties in the development and application of composite materials in aircraft and helicopter engineering, modern science feels optimistic about the future. Many efforts are applied to expand and improve application and production of composite materials. In Russia, state policy is aimed at implementation of scientific activities into practice.

\section{References}

[1] G.P. Svishchev, Aviation. Encyclopedia, Bolshaya Rossiyskaya encyclopedia, Moscow, 1994.

[2] V.M. Shkolnikov "Fuels, lubricants, technical liquids" Assortment and application, 1999, p.596.

[3] E.A. Konyaev, M.L. Niemczyk "Aviation fuels and lubricants” MSTU GA, 2013, p. 80 .

[4] A.I. Elshin "ANKhK oil Refinery. They were first. The pages of history 1955 - 1975", Reprotsentr A1, Irkutsk, 2017, p. 188.

[5] V.M. Nechaev, I.F. Tkachev "Combustive-lubricating materials and special fluids" FGOU VPO "Saint-Petersburg state University of civil aviation, 2008, p. 73.

[6] K.K. Folders "Motor and jet oils and liquids" Publishing house "Chemistry", 1982 p.245.

[7] G.V. Barabanova, L.N. Rudavets, M.A. Evstratova "Improving the performance of aircraft fluid ngzh-5U," The World of petroleum products, pp. 20-22, 2014.

[8] M.A. Ershov, V.E. Emelyanov "the Resumption of production of aviation fuel in Russia. Problems and prospects," World oil, Vol.11, pp. 17, 2014.

[9] E.A. Derevianko "Development and implementation of modern technologies of production and application of high-energy thermostable fuels for rocket and aircraft technology," World of petroleum products, Vol. 4, pp. 46-47, 2013. 